\title{
A Concept to Improve Care for People with Dementia
}

\author{
Mary Sio Lai Karppinen, Jori Karppinen, Raija Halonen* \\ *University of Oulu, Faculty of ITEE, M3S, Finland, raija.halonen@oulu.fi \\ Institution, Department, City, Country, Institution, Department, City, Country,
}

\begin{abstract}
Dementia is one of the severe causes of mortality in elder groups of human population, and the number of dementia patients is expected to increase all over the world. Globally, the cost to take care of patients with the illness is high. Moreover, the lives for dementia patients are commonly impacted by a variety of challenges, for example in terms of communication, emotional behaviour, confusion and wandering. Therefore, the future aim is to develop a serious games package which can help to slow down the progression of dementia, better life for the patients and their loves one, and reduce the use of medications and the cost for the government sectors. In this study, a conceptual model was formed to present the problems the dementia patients and their caregivers are facing, and non-pharmacological approaches are suggested to slow down the progression of dementia-related impairments and behavioural symptoms by using well structured serious games with personalised data.
\end{abstract}

Keywords: dementia, Alzheimer's disease, ICT technologies, elderly healthcare, gamification, serious games

\section{Introduction}

The purpose of the current study was to two-fold: first, find knowledge about the problems that people suffering from dementia and their caregivers are facing, and second, see if there are means to slow down the progression of dementia-related symptoms with the help of non-pharmacological approach, in this case with the help of ICTenabled games.

The number of dementia cases is increasing year by year all over the world. There are approximately 50 million people worldwide diagnosed with dementia [1] and Alzheimer's disease is the most common cause of dementia [2]. There are many direct and indirect costs for the society in taking care of this group of patients and this has become a huge burden for every countries in the world [3].

At the time of the study, no cure of Alzheimer's disease is reported. Since 2003, not even a new treatment option is published in the clinical market. [4] However, there already are interventions for people suffering from dementia focusing on different technologies. On the other hand, the role of social health and social participation as objectives is not established so far. There are studies that propose positive findings related to computer-based cognitive interventions carried out with people with dementia, and earlier knowledge proposes that people suffering from dementia can benefit from ICTbased applications that support the demented people to facilitate and create social networks. $[5,6]$. 
In general, the behavioural and psychological symptoms of dementia should be managed with non-pharmacologic care if possible, and the management of those symptoms form an important part of the care plan. In this sense, the practices and treatment should be evaluated frequently. [7] A recent study [8] of serious games in healthcare showed that the role of serious games is increasing especially to influence education, cognitive rehabilitation, psychology and physical rehabilitation.

The current study wanted to find out how the issues related to ageing people with dementia and other memory related diseases are discussed in earlier research, especially from the viewpoint of non-medical approach, considering also their caretakers. To answer the research question, the earlier knowledge was approached by a mapping study. In addition, a pre-study was carried out to give pre-understanding of the research context and elderly suffering from memory issues.

The current study proposes that carefully designed serious games can support both communication skills as well as reduce emotional problems of the dementia patients. With these improvements, dementia patients are to experience easier, healthier and better lives with their families.

\section{Research approach}

A mapping study is about doing classification and thematic analysis of literature on the chosen topic. In mapping studies, research questions are rather generic than specific. The research question typically asks 'how' and 'what type'. The actual research process is defined by the research area. In the beginning, the scope can be wide and then sharpen when the process progresses. In mapping studies the researcher can choose to focus e.g. on targeted sets of articles or to one or two digital libraries. [9] A systematic mapping study aims at finding research directions while systematic literature study seeks for ways to combine evidence [10]. Papers with empirical research included into the study can be classified into two categories such as validation research or evaluation research, and papers with non-empirical research can be classified into categories such as solution proposals, philosophical papers, opinion papers or experience [11].

A prospective descriptive design was conducted to analyse the use of ICT design and gamification with personalised data to slow down the progression of dementiarelated impairments and to control behavioural symptoms.

In this study, the findings from studies of researches by other scholars and authors were concluded and combined with the result from the primary research. The Google search engine and Google Scholar search engine were used to look for studies within the same or related context. Articles and papers were found with the key words "dementia", "cost for dementia", "caregivers", "behaviour of dementia", "symptoms for dementia", "stages of dementia", "gamification", "gamification health", "gamification dementia" and "personalised information".

These references were selected based on the relevance of the article for the study and the number of citations. The final number of analysed articles was 338 in total. The articles were read through and based on their focus or main content 118 articles were included in the analysis. 


\section{The Study / Literature Review}

According to a 2015 report by World Health Organization (WHO), 47.5 million people by an estimate were living with dementia. Moreover, since then the number of people with the illness has only been increasing. In the report, WHO is projecting the diagnosed cases to triple by the year of 2050. The cost on dementia patients in United States was around 818 billion U.S. dollars in year 2015 and by a forecast, the total cost on this group of people will be around 1 trillion U.S. dollars in 2018 [12]. This sum equals to $1.09 \%$ of the global GDP, which is comparative to the entire annual GDP of countries like Indonesia, the Netherlands or Turkey. Nevertheless, this cost is also larger than the market value of world's largest companies (2017), such as Apple Inc. (752 billion U.S. dollars), Microsoft (507.5 billion U.S. dollars), Amazon.com (427 billion U.S. dollars) and Facebook (407.3 billion U.S. dollars) [14]. Furthermore, the estimated cost on dementia patients will be around 2 trillion by the year 2030, which corresponds to the current total market value of all these companies together [15]. Studies also show the average cost for taking care the group of patients is around $81 \%$ more expensive than patients without dementia, for example while comparing to the costs on heart disease or cancer patients $[16,17]$. Finally, by these figures on diagnosed cases and their tendency of growth, many studies acknowledge dementia as a globally substantial issue $[18,19]$

The percentage of people with dementia in Finland is higher than in European Union (EU) on average. In 2013, this proportion was $1.7 \%$ representing 92,000 people of the entire Finnish population [20]. Furthermore, annually roughly 13,000 new diagnoses are being made, at the same time while a significant proportion of patients die. In addition to personal tragedies caused by disease, from economic and social perspective a person with dementia produces 5,088 euros higher healthcare costs per year than an average citizen [21].

\subsection{Family caregivers' view in taking care of demented family members}

The cost of family caregivers to patients at different stages of dementia is also a significant factor as these groups of people are constantly under stress for example on psychological, practical and financial levels, to mention a few. Moreover, informal caregivers from family can easily develop a problem with depression by taking care of dementia patients $[22,23,24]$. As the family caregivers realise they might need to spend a long time to take care their loved one whose situation with health is getting worse day by day, this might increase their worry and uncertainty for the future. In addition, they may need to alter their plans for everyday life, which may not be able to work out the same as before. Caregivers might also reduce their participation in different kinds of social activities, only to avoid their loved ones behaving inappropriately due to the cause of dementia symptoms. For some people, such arrangements may not be that challenging, however for others it can cause a lot of stress and harm the caregiver's health [23],[25]. Moreover, taking care of a patient with memory disorders takes a lot of time. Therefore, many caregivers need to reduce their working hours or even resign 
from their job to be able to offer enough support to their loved one. $[26,27,28]$. The costs are emphasised on mild and moderate patients with dementia who are mainly taken care by their spouses or kids (in-law) at home [29]. These indirect costs for taking care of dementia can be even doubled to direct costs for a society [23],[29,30,31]. Therefore, this is a clearly increasing the burden of both the communities and the entire world. Although the cost at in-home care is high, there are many positive reasons supporting it. As long as a patient's partner or close relatives are able to look after one, the society should still provide its maximum support for an informal caregiver to look after their patient at a regular home rather than a nursery one, especially at the early stage of the illness. Patients with dementia are more willing to rely and to be taken care by the people they find familiar and trustable. [32]. Family caregivers can give more mental support to the patients and - if they are receiving enough information, support and professional instructions from the society - it is possible for the patient to release their stress by taking care the loved one and even improve the overall relationships within the family [25],[31].

\subsection{Difficulties of people having symptoms of dementia}

The fact sheet published by WHO (2017) describes dementia as commonly a longer term and gradually decreasing ability to think and remember, having an impact on a person's daily functioning. Thus, in addition to issues with memory loss being individual to every patient, it also impacts on the surrounding society they live in [19], [22], [33]. As the disease evolves, a varying set of difficulties are either directly or indirectly faced by both patients are their loved ones. These are commonly experienced in form of symptoms such as - but are not limited to - communication [34,35,36,37], emotional $[38,39]$ behavioural $[40,41,42]$ and wandering $[43,44,45,46,47]$ and comprehension [35], [48,49,50] problems.

Communication is the most common challenge people diagnosed with dementia are facing each day. Generally, patients with dementia start to lose the ability in finding words $[51,52,53,54]$. Moreover, they may also not be able to fully understand and interpret surrounding conversations and words in a usual manner. Dementia is causing it difficult for some patients to catch part of the instruction or information in the whole discussion and therefore might understand it incorrect. [55] As the illness progresses, patients with dementia might no longer communicate with other people as fluently as usual. Due to this, it is possible for patients to lose their confidence, increase depression and feel more moody [51],[56,57,58]. Furthermore, losing the ability to communicate can path dementia patients way to emotional problems, having to experience anxiety, frustration, anger and depression [44],[59,60]. These symptoms may also exist when the patient start to reply more others to complete their daily tasks, unable to maintain their interest and participating in different activities, brain disorder and presence of physical symptoms such as pain, loss of appetite and lack of energy deal to the dementia disease $[61,62]$.

Furthermore, the behaviour of people diagnosed with dementia also changes as the illness progresses [60]. The dementia patients might start doing the same things repeatedly, as well as time to time behaving restless, sleepy, wandering, screaming and being 
physically aggressive $[62,63,64,65]$. It is common for dementia patients to wander. Nevertheless, this behaviour is very exhaustive to the caretakers as patients might put themselves into danger, such as getting into an accident, lost and confused. This inappropriate behaviour might interfere notably with daily activities of the patients and their caretakers. [44].

Finally, brain degeneration effects on the patient's ability to comprehend. Impairment of comprehension is a factor very necessary to be considered while observing the performance of patients. Based on the findings processing words is a significant problem for most of these people with dementia $[66,67,68]$. Complex, long, passive sentences or ones with new words are always difficult for dementia patients to understand [67],[69].

In all, the difficulties bring caretakers a burden to apply more physical efforts while looking after their patients. In addition, the risk of their mental stress is increasing.

\subsection{Different diagnosis in early, middle and later stages of dementia}

Dementia progress is often divided into three different stages, which are early dementia, middle dementia and late dementia $[70,71,72]$. In the early stage of dementia, symptoms might not be very visible. Patients might only make mistakes - as an example - with days, names of people or items, daily tasks, metaphysical thinking or having difficulties in drawing simple pictures. Moreover, the patients may not sleep restlessly and have as stable emotions as normally. At their early stage of dementia, people are able to take care themselves independently, only not as smoothly as before with their normal health. People around the patient may not immediately recognise such behaviour as signs for the patient getting diagnosed with dementia [73,74,75].

Typically, patients will move to the middle stage of their disease. At this stage, symptoms are getting more obvious, dementia patients might start to lose a direction in areas familiar to them. The patients are commonly experiencing difficulties in understanding instructions and information, problems in concentration and emotions, for example becoming more moody or violent [2],[76,77]. The patients may also behave inappropriately in public areas, experiencing frustration [78].

Finally, at the late stage of dementia, individuals with the illness may not be able to take care themselves while performing daily tasks, such as eating, bathing and dressing up. At this terminal phase, some may no longer be able to read, write, talk, walk or recognise people they used to know. Normal conversations with the patients are almost impossible. Their personality might totally change and become more emotional. Typically to these patients, crying and screaming might happen. Furthermore, the patients might not have much energy to participate in their usual hobbies $[79,80]$. As the level and nature of the symptoms at different stages of dementia patients are various, it is also assumed the impact of serious games varies from one patient to another.

\subsection{Using personalised information to decrease the problems}

Although the symptoms of dementia reduce a person's ability to maintain their daily routines, the studies found that communication, emotion, behaviour and comprehension 
problems can be improved if subjects of discussions are related to their personal preferences. Patients are more interested to speak about topics which they are familiar with. These topics are usually related with one's own life stories or memories, which are having a positive and significant role or impact on the person directly $[81,82,83,84]$. Topics which are related with the patient's' history are always easier to chat and share with the patient [85], and better communication will increase the patient's self-confidence [86].

Moreover, this interest can be encouraged with pictures or video recognisable by the patients. Patients with dementia can remember better and have a more clear picture about their past than what has happening around them recently. [84] Creating an environment with pictures, video or music, which match with the individual interest or background, can help in stabilising the patient's emotion and behaviour [86]. Older, personal memories relevant to the individual always have a higher chance to be remembered by patients diagnosed with dementia [87].

Furthermore, discussions on special events belonging to the dementia patient's own culture can also stimulate one's memory and improve performance on communication [88]. As dementia individuals can remember things in the past better, the best contextual to support this group of patients are the items or pictures that they are familiar with. The suggestion of writing a life story books, memory books, family albums and memory boxes have been widely introduced in many researches, associations and communities $[89,90]$. People from different nations and environment will develop different habits, interests and value to their lifestyle and history [91]. Understanding the culture, history background and interests of a dementia patient can let them feel more willing and comfortable to maintain their interest in communication. This can stimulate the patient's verbal skills and exploration. Finally, due to the brain degeneration issue, language comprehension ability of people diagnosed with dementia will decline, however with contextual support, patient can also have a better understanding of conversations and instructions. [67].

\subsection{Gamification impact in health care}

Gamification is about applying game design elements in non-game contexts [92]. Generally, gamification is a process for applying game design elements in motivating users to participate and achieve a positive result in their performance [93,94]. It can also change the behaviour of a person through 'playing' with the 'games' [93],[95,96,97]. A survey reported that $65 \%$ of the cases under study showed gamification having a positive impact on encouraging end-user participation, and $32 \%$ of the cases claimed that gamification elements have a capability to change behaviour [98].

Thanks to the development of modern technological solutions, such as laptops, tablets and smartphones, gamification has been widely used in many different areas $[99,100,101,102]$. For example, in marketing industry, the role of gamification is to modify customer's behaviour, increase customer engagement and awareness, and maintain customers' loyalty $[103,104,105]$. Moreover, gamification is used for educational purpose. It can motivate students to learn and achieve better result in their studies by receiving more accurate feedback [102],[106,107]. Studies show that through 'gaming', 
users can be educated to become more efficient and productive. Furthermore, it will also motivate them to practice learning and apply the skills in their studies or work [105],[108]. Many researches and studies indicate that positive elements - such as passion in learning and engagement [109], which comes along with gamification - are very valuable and beneficial in improving a service and the health and wellbeing of patients [110]. Gamification can help in educating the public to understand and promote different health related information [97],[111]. More importantly, gamified systems can also be applied to healthcare designed training by motivating the patients to exercise more, as a result of better improvement in their health [18],[112,113,114].

Related to gamification in supporting patients with dementia, there are suggestions that non-pharmacological therapies might offer appealing alternatives for treatment of cognitive symptoms. In addition, serious games can positively address people's condition with dementia and improvements can be found particularly from emotional, behavioural and social aspects [113]. Gamified training can increase the enjoyment for patients to continue their participation in brain training exercises, and as a result, both 'self-confidence' and 'self-rated memory' are advanced [114]. Combined with the importance of personalised information in improving the communication of dementia patients [85], serious game systems with personalised content have the potential to improve the power of gamification and enhance the life quality of dementia patients.

Table 1. Concepts and papers.

\begin{tabular}{|l|l|}
\hline Communication & $34 ; 35 ; 36 ; 37 ; 51 ; 52 ; 53 ; 54 ;$ \\
\hline Emotion & $38 ; 39 ; 44 ; 51 ; 56 ; 57 ; 58 ; 59 ; 60 ; 61 ; 62$ \\
\hline Behaviour & $40 ; 41 ; 42 ; 43 ; 44 ; 45 ; 46 ; 47 ; 60 ; 62 ; 63 ; 64 ; 65$ \\
\hline Comprehension & $35 ; 48 ; 49 ; 50 ; 66 ; 67 ; 68 ; 69$ \\
\hline Personalized information & $67 ; 81 ; 82 ; 83 ; 84 ; 85 ; 86 ; 87 ; 89 ; 90 ; 91$ \\
\hline Gamification & $\begin{array}{r}92 ; 93 ; 94 ; 95 ; 96 ; 97 ; 98 ; 99 ; 100 ; 101 ; 102 ; 103 ; 104 ; 105 ; \\
106 ; 107 ; 108 ; 109 ; 110 ; 111 ; 112 ; 113 ; 114\end{array}$ \\
\hline
\end{tabular}

Table 1 summarises the grounds of this study by identifying references reviewed for each topic of this paper.

\section{$4 \quad$ Findings}

In this study the findings are presented as a conceptual framework (Fig.1). 


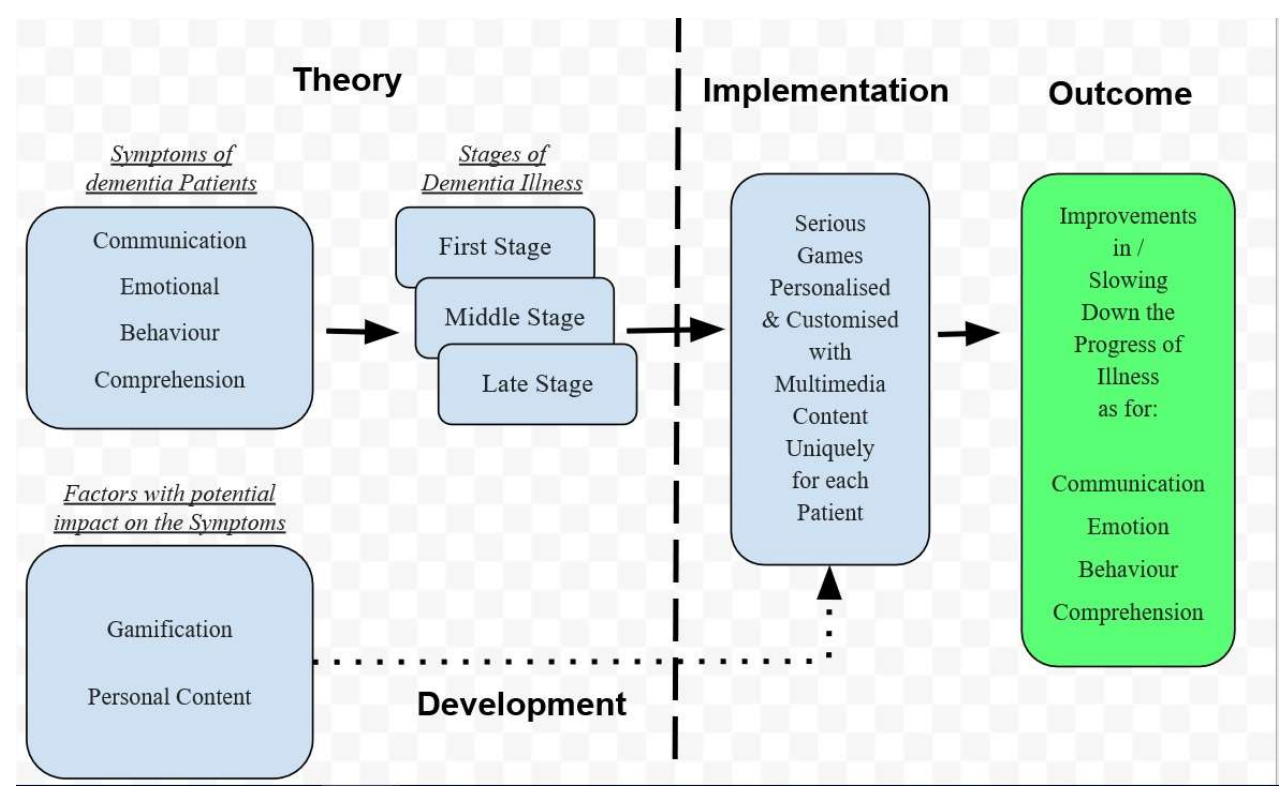

Fig. 1. The proposed conceptual framework.

The literature studies suggested that problems related to communication [35],[37], emotional [39], behavioural [41], wandering [44],[46], and comprehension [48],[50] are the most common symptoms for individuals in early, middle and later stages of dementia [70]. On the other hand, personal content can motivate dementia patient's interest in communication [85] and serious games may have a positive impact on patient's emotion, behaviour and sociability ability [113]. Based on the findings from referenced literature studies and the approach introduced in the conceptual framework of this paper, serious games tailored with personalised content is expected to influence on the patient's daily routines and potentially the quality of life.

Future development and studies will evaluate if the proposed conceptual framework shows potential in managing behavioural symptoms at different stages of dementia, while applied to well-designed serious games with personalised content.

\section{Discussion and Conclusions}

The purpose of the paper was to identify potential means to slow down the progression of dementia-related symptoms with the help of a non-pharmacological approach. As a part of the conceptual framework, a technological approach to the non-pharmacological method was introduced.

Dementia is one of the severe causes of mortality in elder groups of human population. The studies estimate that the number of dementia patients is to increase all over the world [2]. Moreover, the cost for the world to take care of patients with dementia is high and further growing [12]. In order to reduce the countries' burden for taking care the illness and improve the quality of their lives, solutions of helping this group of 
people are needed. The current study proposed a concept (see Fig. 1) that opens new possibilities to support people with lower costs.

Senior citizens are willing to use new technologies if they are well informed about the provision of usable technologies and have gathered positive experiences in using them [115]. The advantages of applying gamification on patients in healthcare sectors have already been identified and reported in many researches [18],[110],[112]. On the other hand, based on the literature studies, the chances for people to get diagnosed with dementia will start to increase rapidly from 65 years on [19],[116,117,118]. This is the age group at risk and in target for researches. Therefore, it is presumable that after experiencing the initial phase of dementia, some of their skills for using information systems are still present. Furthermore, personal content can motivate dementia patient's interest in communication [85] and serious games have a positive effect on patient's emotion, behaviour and sociability [113]. However, the power of personal content with serious gaming has not been researched and tested. Therefore, a conceptual framework (Fig. 1) was constructed. The conceptual framework will guide analysing if serious games with content personalised for dementia patients diagnosed into one of the three different phases of dementia (first stage, middle stage and late stage) can bring new ways to meet the patients and to support their lives. The current study proposes that the conceptual framework will offer new knowledge to be applied when seeking for reliable and realistic data on the impact of serious gaming with personalised content on dementia, and explore its possibilities to be used as a non-pharmacological method of treatment.

In the future, further interviews, prototyping and targeted field trials on audiences possessing a risk for dementia are needed. Academic collaborators from the field of research and development (R\&D) are introduced with the concept and invited to work together on the second phase of the project, development of a prototype for the target group. Future studies are aiming at developing a real-life prototype consisting of an interactive, gamified $\mathrm{Web} /$ mobile based application for storing and consuming personal, familiar memories presented in form of images, videos, sounds (voice), graphics and colours. The findings and feedback are concluded with the resulting prototypes of a serious game and its impact on dementia patients at different stages of their illness. More studies are needed to conclude the value of gamified, interactive and personal $\mathrm{Web} /$ mobile solutions for lives of dementia patients.

\section{$\underline{\text { References }}$}

1. World Health Organization, WHO launches Global Dementia Observatory. http://www.who.int/mental_health/neurology/dementia/en/ (2018)

2. Alzheimer's Association, What Is Alzheimer's?. https://www.alz.org/alzheimers_disease what is alzheimers.asp (2018)

3. Boseley, S.:Dementia research funding to more than double to $£ 66 \mathrm{~m}$ by 2015 . The Guardian. London, https://www.theguardian.com/society/2012/mar/26/dementia-research-funding-to-double (2012)

4. Mishra, C. B., Kumari, S., Manral, A., Prakash, A., Saini, V., Lynn, A. M., \& Tiwari, M.: Design, synthesis, in-silico and biological evaluation of novel donepezil deriva- 
tives as multi-target-directed ligands for the treatment of Alzheimer's disease. European Journal of Medicinal Chemistry, 125, pp. 736-750. https://doi.org/10.1016/j.ejmech.2016.09.057 (2017)

5. Pinto-Bruno, Á. C., García-Casal, J. A., Csipke, E., Jenaro-Río, C., \& Franco-Martín, M.: ICT-based applications to improve social health and social participation in older adults with dementia. A systematic literature review. Aging \& Mental Health, vol. 21(1), 58-65. http://dx.doi.org/10.1080/13607863.2016.1262818 (2017)

6. García-Casal, J. A., Loizeau, A., Csipke, E., Franco-Martín, M., Perea-Bartolomé, M. V., \& Orrell, M.: Computer-based cognitive interventions for people living with dementia: a systematic literature review and meta-analysis. Aging \& Mental Health, vol. 21(5), pp. 454-467 https://doi.org/10.1080/13607863.2015.1132677 (2017)

7. Robert, P.H., König, A., Amieva, H., Andrieu, S., Bremond, F., Bullock, R., Ceccaldi, M., Dubois, B., Gauthier, S., Kenigsberg, P.A., Nave, S., Orgogozo, J.M., Piano, J., Benoit, M., Touchon, J., Vellas, B., Yesavage, J., Manera, V.: Recommendations for the use of Serious Games in people with Alzheimer's Disease, related disorders and frailty. Frontiers in Aging Neuroscience, 6:54 (2014)

8. Korhonen, T. \& Halonen, R.: Serious games in healthcare: Results form a systematic mapping study. 30th Bled eConference: Digital Transformation - From Connecting Things to Transforming Our Lives, pp. 349-368 (2017)

9. Kitchenham, B. A., Budgen, D., \& Brereton, O. P.: Using mapping studies as the basis for further research-a participant-observer case study. Information and Software Technology, 53(6), vol. 638-651 (2011)

10. Petersen, K., Vakkalanka, S., \& Kuzniarz, L.: Guidelines for conducting systematic mapping studies in software engineering: An update. Information and Software Technology, vol. 64, pp. 1-18 (2015)

11. Wieringa, R., Maiden, N., Mead, N., \& Rolland, C.: Requirements engineering paper classification and evaluation criteria: A proposal and a discussion. Requirements Engineering, vol. 11(1), pp. 102-107. doi:10.1007/s00766-005-0021-6 (2006)

12. Alzheimer's Disease International, Dementia statistics: https://www.alz.co.uk/research/statistics (2015)

13. Wimo, A.; Guerchet, M.; Ali, G.C.; Wu, Y.T.; Prina, A.M.; Winblad, B.; Jonsson, L.; Liu, Z.; Prince, M.: The worldwide costs of dementia 2015 and comparisons with 2010. vol.13 , pp. 1-7. Alzheimers Dement (2017)

14. Statista, Inc., The 100 largest companies in the world by market value in 2017 (in billion U.S. dollars). https://www.statista.com/statistics/263264/top-companies-in-theworld-by-market-value/ (2017)

15. Prince, M., Wimo, A., Guerchet, M., Ali, G.C., Wu, Y.-T., \& Prina, M.,: The World Alzheimer Report 2015, The Global Impact of Dementia: An analysis of prevalence, incidence, cost and trends. Alzheimer's Disease International, https://www.bupa.com/ /media/files/site-specific-files/our\%20purpose/healthy\%20ageing\%20and\%20dementia/war\%202015/world-alzheimer-report2015.pdf (2015)

16. Donna, R., Time Inc., Coping With the Costs of Dementia: The Middle Stage. http://time.com/money/4120981/dementia-costs-middle-stage/ (2015)

17. Gina, K., Costs for Dementia Care Far Exceeding Other Diseases. The New York Times, https:/www.nytimes.com/2015/10/27/health/costs-for-dementia-care-far-exceeding-other-diseases-study-finds.html (2015)

18. McCallum, S.: Gamification and serious games for personalized health. Studies in health technology and informatics, 177, pp. 85-96 (2012)

19. Alzheimer's Association: Alzheimer's disease facts and figures. Alzheimer's \& Dementia, vol. 13(4), 325-373 (2017) 
20. Alzheimer Europe: 2013: The prevalence of dementia in Europe (Finland): http://www.alzheimer-europe.org/Policy-in-Practice2/Country-comparisons/2013The-prevalence-of-dementia-in-Europe/Finland (2014)

21. ScienceNewsline, Alzheimer's patients' health care costs higher already before diagnosis: Finnish study. http://www.sciencenewsline.com/news/2015111617430034.html (2015)

22. Beach, S. R., Schulz, R., Yee, J. L., \& Jackson, S.: Negative and positive health effects of caring for a disabled spouse: Longitudinal findings from the Caregiver Health Effects Study. Psychology and Aging, vol.15(2), pp.259-271 (2000)

23. Carroll, L.: Alzheimer's extracts a high price on caregivers, too. Today, http://www.today.com/health/alzheimers-extracts-high-price-caregivers- too-8C11070658 (2013)

24. Alzheimer's Association and National Alliance for Caregiving: Families care: Alzheimer's Caregiving in the United States 2004. Alzheimer's Association, https://www.alz.org/national/documents/report_familiescare.pdf (2004)

25. Acton, G.J., \& Wright, K.B.: Self-transcendence and family caregivers of adults with dementia. Journal of Holistic Nursing, vol.18(2), pp. 143-158 (2000)

26. Chambers, M., Ryan, A.A., \& Connor, S.L.: Exploring the emotional support needs and coping strategies of family carers. Journal of Psychiatric and Mental Health Nursing. Apr 8(2), pp. 99-106 (2001)

27. Prince, M.: Care arrangements for people with dementia in developing countries. International Journal of Geriatric Psychiatry. Feb 19(2), pp. 170-177 (2004)

28. Papastavrou, E., Kalokerinou, A., Papacostas, SS., Tsangari, H., \& Sourtzi, P.: Caring for a relative with dementia: family caregiver burden. Journal of Advanced Nursing, June 58(5), pp. 446-57 (2007)

29. Schwarzkopf, L., Menn, P., Kunz, S., Holle, R., Lauterberg, J., Marx, P., Mehlig, H., Wunder, S., Leidl, R., Donath, C., \& Graessel, E.: Costs of care for dementia patients in community setting: an analysis for mild and moderate disease stage. Value in Health, vol. 14(6), pp.827-835 (2011)

30. Beeri, M.S., Werner, P., Davidson, M., \& Noy, S.: The cost of behavioral and psychological symptoms of dementia (BPSD) in community dwelling Alzheimer's disease patients. The International Journal of Geriatric Psychiatry, vol. 17(5),:pp. 403-408 (2002)

31. Brown, R.M., \& Brown, S.L.:Informal caregiving: A reappraisal of effects on caregivers. Social Issues and Policy Review, vol. 8(1), pp. 74-102 (2014)

32. Carbonneau, H., Caron, C., \& Desrosier, J.: Development of a conceptual framework of positive aspects of caregiving in dementia. Dementia vol 9(3), pp. 327-353 (2010)

33. Lamping, D.L., Banerjee, S., Harwood, R., Foley, B., Smith, P., Cook, J.C., Murray, J., Prince, M., Levin, E., Mann, A., \& Knapp, M.: Measurement of health-related quality of life for people with dementia: development of a new instrument (DEMQOL) and an evaluation of current methodology. Health Technol Assess, vol.9(10), pp. 1-93 (2005)

34. Burgio, L., Allen-Burge, R., Stevens, A., Davis, L., \& Marson, D. . Caring for Alzheimer's disease patients: Issues of verbal communication and social interaction. In J. M. Clair \& R. M. Allman (Eds.), The gerontological prism: Developing interdisciplinary bridges, pp. 231-258 (2000)

35. Altmann, L.J., \& McClung, J.S.: Effects of semantic impairment on language use in Alzheimer's disease. Seminars in Speech and Language, vol. 29 (1), pp. 18-31 (2008)

36. Bayles, K.A., Tomoeda, C.K. \& Trosset, M.W.: Relation of linguistic communication abilities of Alzheimer's patients to stage of disease. Brain and Language, vol. 42 (4), pp. 454-472 (1992)

37. Honig, L.S., \& Mayeux, R.: Natural history of Alzheimer's disease. Aging Clinical and Experimental Research, vol. 13(3), pp. 171-182 (2001) 
38. Magai, C., Cohen, C., Gomberg, D., Malatesta, C., \& Culver, C.: Emotional expression during mid- to late-stage dementia. International Psychogeriatrics, vol. 8(3), pp. 383395 (1996)

39. The Alzheimer Society of Ireland: Understanding late stage dementia - Alzheimer Society of Ireland. https://www.alzheimer.ie/Alzheimer/media/SiteMedia/Helpline $\% 20$ and $\% 20$ Information $\% 20$ Resources/Info $\% 20 \mathrm{Pack} \% 20 \mathrm{PDF} \% 27 \mathrm{~s} /$ Understanding-late-stage-dementia SectionA6.pdf

40. Finkel, S.: Behavioral and psychological symptoms of dementia: a current focus for clinicians, researchers, and caregivers. The Journal of Clinical Psychiatry, vol. 62(Suppl 21), pp. 3-6 (1998)

41. Cipriani, G., Vedovello, M., Nuti, A., \& Di Fiorino., M.: Aggressive behavior in patients with dementia: correlates and management. Geriatrics and Gerontology International, vol. 11(4), pp. 408-413 (2011)

42. Teri, L., Truax, P., Logsdon, R., Uomoto, J., Zarit, S., \& Vitaliano, P.P.: Assessment of behavioral problems in dementia: The revised Memory and Behavior Problems Checklist. Psychology and Aging, vol. 7, pp. 622 -631 (1992)

43. Robinson, L., Hutchings, D., Dickinson, H.O., Corner., L., Beyer., F., Finch., T., Hughes, J., Vanoli, A., Ballard, C., \& Bond, J.: Effectiveness and acceptability of nonpharmacological interventions to reduce wandering in dementia: a systematic review. International Journal of Geriatric Psychiatry, vol. 22, pp. 9-22 (2007)

44. Cipriani, G., Lucetti, C., Nuti, A., \& Danti, S.: Wandering and dementia. Psychogeriatrics, Vol. 14(2), pp. 135-42 (2014)

45. Hope, R.A., \& Fairburn, C.G.: The nature of wandering in dementia-a community based study. International Journal of Geriatric Psychiatry, vol. 5, pp. 239-245 (1990)

46. Yong, T. K., Young, S.Y., \& Koo, M.S.: Wandering in Dementia. Dement Neurocognitive Disord, vol.14(3), pp. 99-105 (2015)

47. Rosato, D.: Coping With the Costs of Dementia: The Middle Stage. Money. http://time.com/money/4120981/dementia-costs-middle-stage/ (2015)

48. Jefferies, E., Patterson, K., Jones, R.W., \& Lambon Ralph, M.A.: Comprehension of concrete and abstract words in semantic dementia. Neuropsychology, vol. 23(4) pp. 492-499 (2009)

49. Grossman, M., D'Esposito, M., Hughes, E., Onishi, K., Biassou, N., White-Devine, T., \& Robinson, K.M.: Language comprehension profiles in Alzheimer's disease. Neurology, vol. 47(1) pp. 183-189 (1996)

50. de Carvalho, I.A., \& Mansur, L.L.: Validation of ASHA FACS-functional assessment of communication skills for Alzheimer disease population. Alzheimer Dis Assoc Disord, vol.22(4), pp. 375-381 (2008)

51. Killick, J., \& Allen, K.: Communication and the care of people with dementia. Buckingham: Open University Press (2001)

52. Blair, M., Marczinski, C. A., Davis-Faroque, N. \& Kertesz, A.: A longitudinal study of language decline in Alzheimer's disease and frontotemporal dementia. Journal of the International, vol. 13, pp.237-245 (2007)

53. Bohling, H. R.: Communication with Alzheimer's patients: an analysis of caregiver listening patterns. International Journal of Aging \& Human Development, vol. 33(4), pp. 249-267 (1991)

54. Dementia Care Central, How to Communicate with Someone with Dementia, https://www.dementiacarecentral.com/about-us/ (2018a)

55. Stokes, G.: Tackling communication challenges in dementia, Nursing Times, vol. 109(8), pp. 14-15 (2013) 
56. Thomas, P., Lalloué, F., Preux, P.M., Hazif-Thomas, C., Pariel, S., Inscale, R., Belmin, J., \& Clément, J.P.: Dementia patients caregivers quality of life: The PIXEL study. International Journal of Geriatric Psychiatry, vol. 21(1), pp. 50-56 (2006)

57. Yahya, A., Chandra, M., An, K.S., \& Garg, J.: Behavioral and psychological symptoms in dementia and caregiver burden. Clinical Medicine Research, vol.4(2-1), pp. 8-14 (2015)

58. Prado-Jean, A., Couratier, P., Druet-Cabanac, M., Nubukpo, P., Bernard-Bourzeix, L., Thomas, P., Dechamps, N., Videaud, H., Dantoine, T., \& Clément, J. P.: Specific psychological and behavioral symptoms of depression in patients with dementia. International Journal of Geriatric Psychiatry, vol. 25(10), pp. 1065-1072 (2010)

59. Dementia Care Central, Dementia Emotional Problems - Depression, https://www.dementiacarecentral.com/caregiverinfo/coping/emotions/ (2018b)

60. Kim, S.Y.: Behavioral and psychological symptoms of dementia. Korean. Dementia Association, vol. 3 (1), pp. 14-17 (2004)

61. Herbert, J., \& Lucassen, P.J.: Depression as a risk factor for Alzheimer's disease: genes, steroids, cytokines and neurogenesis - What do we need to know? Frontiers in Neuroendocrinology, vol. 41, pp. 153-171 (2016)

62. Rongve, A., Boeve, B.F., \& Aarsland, D.: Frequency and correlates of caregiver-reported sleep disturbances in a sample of persons with early dementia. Journal of the American Geriatrics Society, vol. 58(3), pp. 480-486 (2010)

63. Kim, H.: Behavioral and Psychological Symptoms of Dementia. Ann. Psychiatry Ment. Health, vol. 4(7), pp. 1086 (2016)

64. Cerejeira, J., Lagarto, L., \& Mukaetova-Ladinska, E. B.: Behavioural and psychological symptoms of dementia. Frontiers in Neurology, vol. 3(73), pp. 1-21 (2012)

65. Yesavage, J. A., Friedman, L., Ancoli-Israel, S., Bliwise, D., Singer, C., Vitiello, M. V., Monjan, A. A., \& Lebowitz, B.: Development of diagnostic criteria for defining sleep disturbance in Alzheimer's disease. Journal of Geriatric Psychiatry and Neurology, vol.16 (3), pp. 131-139 (2003)

66. Reilly, J., Martin, N., \& Grossman, M.: Verbal learning in semantic dementia: Is repetition priming a useful strategy? Aphasiology, vol.19 (3-5), pp. 329-339 (2005)

67. Weirather, R.R.: Communication Strategies to Assist Comprehension in Dementia. Hawaii Medical Journal, vol. 69(3), pp. 72-74 (2010)

68. Kempler, D.: Language changes in dementia of the Alzheimer type. In R. Lubinski (Ed.), Dementia and communication: Research and clinical implications, pp. 98-114 (1995)

69. Ni, W., Constable, R.T., Mencl, W.E., Pugh, K.R., Fulbright, R.K., Shaywitz, S.E., Shaywitz, B.A., Gore, J.C., \& Shankweiler, D.: An event-related neuroimaging study distinguishing form and content in sentence processing. Journal of Cognitive Neuroscience, vol. 12(1), pp. 120-133 (2000

70. Muck-Seler, D., Presecki, P., Mimica, N., Mustapic, M., Pivac, N., Babic, A., Nedic, G., \& Folnegovic-Smalc, V.: Platelet serotonin concentration and monoamine oxidase type B activity in female patients in early, middle and late phase of Alzheimer's disease. Progress in Neuro-psychopharmacology \& Biological Psychiatry, vol. 33(7), pp. 12261231 (2009)

71. Dijkstra, K., Bourgeois, M., Petrie, G., Burgio, L., \& Allen-Burge, R.: My Recaller is on Vacation: Discourse Analysis of Nursing-Home Residents With Dementia, Discourse Processes, vol. 33(1), pp. 53-74 (2002a)

72. Dijkstra, K., Bourgeois, M., Burgio, L., \& Allen, R.: Effects of a communication intervention on the discourse of nursing home residents with dementia and their nursing assistants. Journal of Medical Speech-Language Pathology, vol. 10(2), pp. 143-157 $(2002 b)$ 
73. Luke, A., Dementia symptoms: Doing this could be an early warning sign. https://www.express.co.uk/life-style/health/950356/dementia-symptoms-signs-typescauses (2018)

74. Morris-Underhill, C.: Hantsport women team up to create fidget quilts for people with dementia. http://www.hantsjournal.ca/community/hantsport-women-team-up-to-create-fidget-quilts-for-people-with-dementia-204557/ (2018)

75. Van Gool, W.A., Weinstein, H.C., Scheltens, P. \& Walstra, G.J.: Effect of hydroxychloroquine on progression of dementia in early Alzheimer's disease: An 18month randomised, double-blind, placebo-controlled study. Lancet, vol. 358, pp. 455$60(2001)$

76. Shimokawa, A., Yatomi, N., Anamizu, S., Torii, S., Isono, H., Sugai, Y., \& Kohno, M.: Influence of deteriorating ability of emotional comprehension on interpersonal behavior in Alzheimer-type dementia. Brain and Cognition, vol. 47(3), pp. 423-33 (2001)

77. Warshaw, G.A., \& Bragg, E.J.:Preparing the Health Care Workforce to Care for Adults with Alzheimer's Disease and Related Dementias, Health Affairs, Vol. 33(4), pp. 633641 (2014)

78. Alzheimer Society of Canada, Middle stage - what to expect, http://alzheimer.ca/en/Home/Living-with-dementia/Caring-for-someone/Middle-stage (2017)

79. Jefferies, E., Bateman, D., \& Lambon Ralph, M. A.: The role of the temporal lobe semantic system in number knowledge: evidence from late-stage semantic dementia. Neuropsychologia, vol. 43(6), pp. 887-905 (2005)

80. Kovach, C.R., \& Magliocco, J.S.: Late-stage dementia and participation in therapeutic activities. Applied Nursing Research, vol. 11(4), pp. 167-173 (1998)

81. McKeown, J., Clarke, A., Ingleton, C., Ryan, T., \& Repper, J.: The use of life story work with people with dementia to enhance person-centred care. International Journal of Older People Nursing, vol. 5 (2), pp. 148-158 (2010)

82. Westmacott, R., Black, S.E., Freedman, M., \& Moscovitch, M.: The contribution of autobiographical significance to semantic memory: Evidence from Alzheimer's disease, semantic dementia, and amnesia, Neuropsychologia, vol. 42(1), pp. 25-48 (2004)

83. Martin, L.S., \& Beaman, A.: Communication strategies to promote spiritual well-being among people with dementia. Journal of Pastoral Care and Counseling, vol. 59 (1-2), pp. 43-55 (2005)

84. Cheston R.: Stories and metaphors: Talking about the past in a psychotherapy group for people with dementia. Ageing and Society, vol. 16(5), pp. 579-602 (1996)

85. Subramaniam, P., Woods B.:Towards the therapeutic use of information and communication technology in reminiscence work for people with dementia: a systematic review. International Journal of Computers in Healthcare, vol. 1(2), pp. 106-125(2010)

86. Yasuda, K., Kuwabara, K., Kuwahara, N., Abe, S., Tetsutani, N.: Effectiveness of personalised reminiscence photo videos for individuals with dementia. Neuropsychological Rehabilitation, vol.19(4), pp. 603-619(2009).

87. Graham, K.S., \& Hodges, J.R.: Differentiating the roles of the hippocampal complex and the neocortex in long-term memory storage: evidence from the study of semantic dementia and Alzheimer's disease. Neuropsychology, vol. 11(1), pp. 77-89 (1997)

88. Beard, R. L., Knauss, J., \& Moyer, D.: Managing disability and enjoying life: How we reframe dementia through personal narratives. Journal of Aging Studies, vol. 23(4), pp. 227-235 (2009)

89. Ryan, E. B., \& Schindel Martin, L.:Using narrative arts to foster personhood in dementia. In: Backhaus, P. (ed.) Communication in elderly care, London, England: Continuum Press, pp. 193-217 (2011)

90. UK Dementia Directory: How to make a memory book. https://www.dementia.co.uk/products/how-to-make-a-memory-book 
91. Day, K. \& Cohen, U.:The role of culture in designing environments for people with dementia: A study of Russian Jewish immigrants. Environment and Behavior, vol. 52(3), pp. 361-399 (2000)

92. Deterding S, Dixon D, Khaled R, Nacke L. From game design elements to gamefulness: defining gamification. InProc. of the 15th international academic MindTrek conference: Envisioning future media environments $2011 \mathrm{Sep} 28$, Association for Computing Machinery, pp. 9-15 (2011)

93. King D, Greaves F, Exeter C, \& Darzi A.:'Gamification': Influencing health behaviours with games. J R Soc Med. Mar, vol. 106(3), pp.76-78 (2013)

94. Reeves, B. and Read, J.L. Total Engagement: Using Games and Virtual Worlds to Change the Way People Work and Businesses Compete. Harvard Business School Press, Boston, MA (2009)

95. Cugelman, B.: Gamification: what it is and why it matters to digital health behavior change developers. JMIR Serious Games, vol. 1(1), (2013)

96. Hamari, J., Koivisto, J., \& Sarsa, H.:Does gamification work?--a literature review of empirical studies on gamification. In System Sciences (HICSS), 2014 47th Hawaii International Conference on, IEEE, pp. 3025-3034 (2014)

97. Bamidis, P.D., Gabarron, E., Hors-Fraile, S., Konstantinidis, E., Konstantinidis, S., \& Rivera, O.: Gamification and behavioral change: techniques for health social media. In Participatory Health Through Social Media, pp. 112-135 (2016)

98. Seaborn, K., Fels, D.I.: Gamification in theory and action: a survey. International Journal of Human-Computer Studies, vol. 74 , pp. 14-31 (2015)

99. Chin, S.: Mobile technology and gamification: The future is now!, IEEE. Digital Information and Communication Technology and it's Applications (DICTAP) 2014 Fourth International Conference on, pp. 138-143 (2014)

100. Bunchball, I.: Gamification 101: An introduction to the use of game dynamics to influence behavior. White Paper (2010)

101. Combéfis, S., BERESNEVIČIUS, G., \& Dagienè, V.: Learning programming through games and contests: overview, characterisation and discussion. Olympiads in Informatics, vol. 10(1), pp. 39-60 (2016)

102. Muntean, C.I.: Raising engagement in e-learning through gamification." In Proc. 6th International Conference on Virtual Learning ICVL, vol. 1, pp. 323-329 (2011)

103. Lucassen, G., \& Jansen, S.: Gamification in Consumer Marketing-Future or Fallacy?. Procedia-Social and Behavioral Sciences, vol. 148, pp.194-202 (2014)

104. Hamari, J., \& Järvinen, A.: Building customer relationship through game mechanics in social games. M. Cruz-Cunha, V. Carvalho, P. Tavares (Eds.), Business, Technological and Social Dimensions of Computer Games: Multidisciplinary Developments, IGI Global, Hershey, PA (2011)

105. Werbach, K. and Hunter, D.: For the win: How game thinking can revolutionize your business. Wharton Digital Press (2012)

106. Zhuang, Y.; Ma, H.; Xie, H.; Leung, A.C.M.; Hancke, G.P.; Wang, F.L.: When innovation meets evolution: An extensive study of emerging e-learning technologies for higher education in Hong Kong. International Symposium on Emerging Technologies for Education, pp. 574-584 (Springer 2016)

107. Strmeki, D., Bernik, A., \& Radoevi, D.: Gamification in e-Learning: introducing gamified design elements into e-learning systems. Journal of Computational Science, vol. 11(12), pp. 1108-1117 (2015)

108. Topîrceanu, A.: Gamified learning: A role-playing approach to increase student inclass motivation. Procedia Computer Science, vol. 112, pp.41-50 (2017)

109. Lenihan, D.: Health games: a key component for the evolution of wellness programs. Games for Health: Research, Development, and Clinical Applications. vol. 1(3), pp. 233-235 (2012) 
110. Pereira P, Duarte E, Rebelo F, \& Noriega P.: A review of gamification for health-related contexts. International conference of design, user experience, and usability. Springer International Publishing, vol. 8518, pp. 742-753 (2014)

111. Menezes, J., Gusmão, C. \& Machiavelli, J.: A proposal of mobile system to support scenario-based learning for health promotion, Procedia Technology, vol. 9(3), pp. 1142-1148 (2013)

112. Pannese, L., Wortley, D., Ascolese, A.: Gamified wellbeing for all ages - how technology and gamification can support physical and mental wellbeing in the ageing society. In: XIV Mediterranean conference on medical and biological engineering and computing 2016. Springer, Berlin, pp 1281-1285 (2016)

113. Groot, C., Hooghiemstra, A.M., Raijmakers, P.G., van Berckel, B.N., Scheltens, P., Scherder, E.J., van der Flier, W.M., Ossenkoppele, R.: The effect of physical activity on cognitive function in patients with dementia: A meta-analysis of randomized control trials. Ageing Res Rev, 25 pp. 13-23 (2016)

114. Savulich, G., Piercy, T., Fox, C., Suckling, J., Rowe, J.B., O’Brien, J.T., Sahakian, B.J.: Cognitive Training Using a Novel Memory Game on an iPad in Patients with Amnestic Mild Cognitive Impairment (aMCI). International Journal of Neuropsychopharmacology, vol. 20(8), pp. 624-633 (2017)

115. Eisma, R., Dickinson, A., Goodman, J., Syme, A., Tiwari, L., \& Newell, A. F.: Early user involvement in the development of information technology-related products for older people. Universal Access in the Information Society, vol. 3(2), 131-140 (2004)

116. Canadian Study of Health and Aging Working Group: The incidence of dementia in Canada. Neurology, vol. 55 (1), pp. 66- 73 (2000)

117. Lobo, A., Launer, L.J., Fratiglioni, L., Andersen, K., Di Carlo, A., Breteler, M.M.,Copeland, J.R., Dartigues, J.F., Jagger, C., Martinez-Lage, J., Soininen, H., Hofman, A.: Prevalence of dementia and major subtypes in Europe: A collaborative study of population-based cohorts. Neurology vol. 54(11 Suppl 5), S4-9 (2000)

118. Robert, P., Leone, E., Amieva, H., \& Renaud, D.: Managing behavioural and psychological symptoms in Alzheimer's disease. Alzheimer's Disease. Chapter 9, pp. 71-84 (2017) 